\title{
e-RUPI: A Purpose Specific Digital Voucher
}

\author{
Jonika Lamba \\ The NorthCap University, Gurugram, Haryana, India \\ Dr. Esha Jain \\ The NorthCap University, Gurugram, Haryana, India
}

\begin{abstract}
RUPI is an advanced online resolution that has been launched by the National Payments Corporation of India (NPCI) in collaboration with the Department of Financial Services, Ministry of Health and Family Welfare, National Health Authority, and partner banks. It is just like a prepaid voucher that can be used by users to redeem an amount without a card, online payment application, or without accessing internet banking services. The present learning has explored the existing literature and aimed to discuss the merits and demerits of this emerging prepaid voucher, in the period of the COVID-19 pandemic. It has been found that the e-RUPI initiative of the Modi government will be fruitful for the beneficiaries as they will receive a direct benefit. It will be reliable and secure for both companies and customers. It suffers from ICT-related risks such as cyber fraud, hacking, lack of efficiency, and attitude of people towards adoption of this new resolution
\end{abstract}

Key words: e-RUPI, Corruption, Digital Currency, Prepaid Voucher

\section{INTRODUCTION}

The phase of COVID-19 is forcing the people to rethink their business operations, the latest government initiatives in this field are playing a noteworthy role. The era of the digital revolution has been embarking their presence in every field. The use of technology has become an important part of the lives of people. Now, for every small thing, we look for technology support. India, being a developing nation is rapidly adopting emerging technologies such as Blockchain, Artificial Intelligence, Internet of Things, Big Data, and Machine Learning. The application of these technologies has changed the way of business operations. The technology offers diverse benefits which lure businesses to adopt these digital advancements. In India, the instances of corruption are too common. The government has taken stringent steps to curb the menace of this corruption in public departments, but due to lack of proper monitoring, it failed to control corruption to some extent. The role of public officials is commendable in fulfilling their responsibility in making India a nation free of corruption. Slowing India is growing and moving towards the path of digital advancement in governance. The initiatives of the government in the field of e-governance have changed the operations of the public departments and also benefitted them with the application of technology. Now, the government has an online presence of their departments, where the general public has direct access to the information and requisite material to process their applications. With every passing year, India is grooming its vision of Digital India and taking decisions that are fruitful to the individuals. Presently, we are new to digital currency but with time India will be well versed with the application of Cryptocurrency and other digital payments platforms (Ranade \& Joshi 2016). In the present literature, it has been noticed that there is a relationship between e-governance and corruption (Andersen,2009; Mistry \& Jalal, 2012; Kim 2014; Aladwani, 2016), and the use of digital governance have significantly reduced the corruption practices in India. Garg \& Panchal (2017) found that the new view of a cashless economy has many merits such as substantial reduction in robbery, down surge in black money, and improvement of economic growth and development of the nation. On the other hand, there were many challenges also such as cyber fraud, the behavior of people, lack of efficiency in online disbursements, absence of transparency, etc. Sidorenko \& Lykov (2019) examined that digital technologies had played a recommendable role in curbing the practice of corruption. The advanced research in cyber security is providing tools and mechanisms to control the menace of digital fraud. There have been several laws enacted at the national and international level to control the menace of fraud by technocrats. The advancement in the IT sector is commendable but it offers certain challenges and threats also. e-RUPI is an advanced online resolution that has been launched by the National Payments Corporation of India (NPCI) in collaboration with the Department of Financial Services, Ministry of Health and Family Welfare, National Health Authority, and partner banks. It is just like a prepaid 


\section{Yinternational Research Journa}

p-ISSN 2202-2821 e-ISSN 1839-6518 (Australian ISSN Agency)

voucher that can be used by users to redeem an amount without a card, online payment application, or without accessing internet banking services. Either Organisations or Governments will share the e-RUPI with the recipients for an activity or specific objective. There will be no user interface in e-RUPI that helps in maintaining the secrecy of the users and also keep the transactions safe and secure. The needed amount is present in the voucher that ensures speedy completion of a transaction. e-RUPI also ensures reliability in the transactions. This voucher will be beneficial for the corporates, Hospitals, and the ultimate customers. It ensures corruption less economy as intermediaries will be nowhere in this advanced revolution. This is the most imperative step taken by the Government of India to directly assist the needy people. It has numerous applications such as when the government awards a scholarship to a student then, that amount of scholarship will be given in the form of an SMS or Bar code after verifying the identity of the student. With the help of this prepaid voucher, the student can avail his/her scholarship at the time of admission for higher studies, i.e., the specific purpose of the eRUPI. It ensures that funds are not misused by the people and maintained that individuals get due credit. Another instance where the government wants to cover the medical treatment of its officials, in that case, they can issue an e-RUPI with the help of a partnering Bank. The official will receive an SMS or a QR code which he/she can use at the time of availing services of the hospital. This prepaid voucher provides realtime processing of transactions which is beneficial for the service provider. Currently, only 11 banks are live with eRUPI. This advanced revolution will help us to use digital currency safely and securely. This will also help the government to monitor that funds that have been earmarked for a certain purpose, have been used for that specific purpose only. The ultimate aim of the government is to make India, a digital economy with the least instances of corruption. The eRUPI will be an individual and objective-specific digital voucher.

\section{II.Inspiring Literature}

Abu-Shanab et al. (2013) stated that there has been no pragmatic indication regarding the prevalence of managerial exploitation in the digital government. The study built an Arabic language instrument on how e-government can encounter managerial exploitation. The study was founded on Jordanian's insight near this marvel. The findings of the study highlighted the importance of the perception of people concerning corruption in e-government and also established the dependability of the planned dimension.
Aladwani (2016) analyzed the present literature on how corruption is posing threat to digital governance. In developing nations, the adoption of a digital platform for government works has been miserable due to prevailing corruption in the system. The monopolies and corruption by bureaucrats have hampered the moral and good governance practices. Being theoretical learning, it attempted to provide the framework where an audit of e-governance wits can be conducted. The individuals who are the target of the egovernance initiatives did not receive anything in reality.

Andersen (2009) projected the influence of digital governance on curbing corruption with the aid of a panel of 149 nations with two-time annotations. It was found that the estimator vintaged an encouraging and thriftily stimulating result.

Choo (2015) deliberated the features of crypto and virtual monies that may be subjugated to clean corruption takings. The study projected a theoretical intelligence-led AML/CTF approach and recognized three probable research queries to afford indication and lectured detailed breaks in information about corruption, and money valeting/terrorism funding dangers.

Garg \& Panchal (2017) examined the viewpoints of Delhi's population on the cashless economy in the country. The study employed a structured questionnaire and used the percentage method to analyze the data. In the collected data it was found that the new view of a cashless economy has many merits such as substantial reduction in robbery, a down surge in black money, and improvement of economic growth and development of the nation. On the other hand, there were many challenges also such as cyber fraud, the behavior of people, lack of efficiency in online disbursements, absence of transparency, etc.

Kim (2014) conducted a study to examine the association between e-government and anti-corruption with the aid of combined data from 200 diverse nations. It was found that it can serve as an effective tool to reduce the activities of corruption in the nation and e-governance combined with improved public bureaucracies could be beneficial in reducing corruption in public departments.

Lamba \& Jain (2021) meticulously reviewed the necessity for cyber-security amid the digital revolution with the assistance of emerging technologies and also emphases on the application and combination of blockchain and the Internet of Things (IoT) for safeguarding cyber-security in the healthcare industry. It was found in the study that worldwide, progressive technology has been used in managing the flow of data and information, India should focus on upholding the same IT-

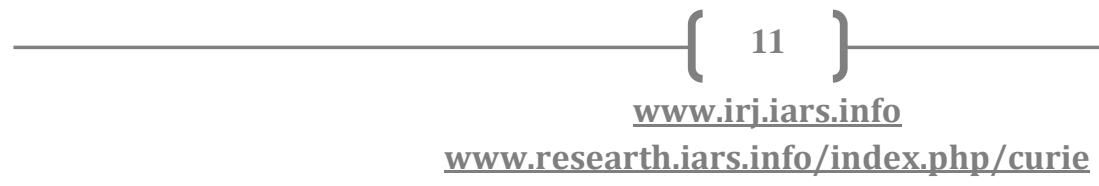




\section{Yinternational Research Journa}

p-ISSN 2202-2821 e-ISSN 1839-6518 (Australian ISSN Agency)

enabled substructure to decrease fates in the nation and on the other hand expand management, confidentiality, and safety in the hospital sector.

Mistry \& Jalal (2012) studied the impact of the application of e-government on corruption around the world and it also examined the impact of the same in developed and developing nations. The outcomes recommended that an increase in the application of digital techniques in the field of e-government decreases corruption. During the seven-year phase between 2003 and 2010, it was also found that the impact of egovernment is higher in developing nations than in developed nations.

Narayanan (2020) emphasized the concept of digital currency, how time had changed the form of money from earlier times. The process of digitalization has molded the concept of digital money. The application of digital currency has a global impact. In the wake of COVID-19, the future of digital currency is bright.

Setor et al. (2021) used a global panel dataset of digital outflows and Transparency International's Corruption Perception Index (CPI), the learning discovered the association between digital payment dealings and exploitation in 111 evolving republics from the year 2010 to 2018. The findings of the study were based on a fixed-effects investigation, which showed that digital dealings decrease bribery and fraud. The study had huge implications for curbing the menace of corruption in emerging nations.

Shah (2017) intended to give an overview of digital currency. The study explained the processing, working, and factors impacting the application of digital currencies. The study highlighted various risks related to digital currency such as lack of transparency, cyber fraud, the attitude of people, lack of efficiency, etc.

Sidorenko \& Lykov (2019) examined that digital technologies had played a recommendable role in curbing the practice of corruption. The emerging techniques such as blockchain, AI, Big Data, and IoT helped in digital outlook and solved the social problems to a certain level. Even the rate of crime has also reduced. Due to the imperfection in the laws, there have been some inadequacies in current models.

\section{The objective of the Study}

The aim of the study is as follows:

- To study the merits and demerits of e-RUPI contactless payment vouchers.
Vol. 11 No. 022021

828011022021174 (C) Author(s)

- To study the scope and future implications of e-RUPI advanced online resolution in the Indian economy.

\section{Research Methodology}

This article meticulously reviews the present literature published in peer-reviewed journals related to the egovernance initiative, corruption, digital payment apps, and the cashless economy. The information gathered in this study has been taken from authentic sources of secondary data collection including past studies and articles. The study is a descriptive analysis of the e-RUPI prepaid voucher launched by honorable PM Narendra Modi on 2nd August 2021. The paper throws some light on the applications as well as merits and demerits of the e-RUPI recently launched payment mechanism to ensure security and integrity in the phase of digital transformation.

\section{V.Discussion}

\section{A. Scope of e-RUPI}

The e-RUPI has a promising future as it's an emerging way of electronic currency. Initially, this pre-paid voucher has tied up with more than 1600 hospitals where this e-currency can be redeemed. The user base of this digital currency will be widened by the passage of time. Due to its benefits, it is expected that it will become popular among the public very soon. e-RUPI will be adopted by the private sector also where they can provide benefits to their employees in the form of this prepaid voucher. The MSMEs can also use this voucher for the execution of their business-to-business transactions. It is predicted that more banks and acquiring Apps will join this egovernance initiative in near future.

\section{B. Merits of e-RUPI}

Convenient to the Consumer

- Users of e-RUPI are not required to carry physical proof of the voucher with themselves.

- Users are not required to share any personal data at the time of redemption so that confidentiality can be maintained.

- Users of e-RUPI of this advanced resolution are not supposed to have a bank account, online net banking, or any online application to execute transactions via eRUPI.

- Direct benefit to the beneficiaries and intermediaries will be rolled out from the system. 
- Customers can use e-RUPI even in feature phones, so having a smartphone is not mandatory for using eRUPI.

- Customers don't require an internet connection for the usage of e-RUPI. So, internet connectivity is not a barrier in the application of e-RUPI.

- The e-RUPI is free from digital risks such as ransomware, theft of personal information, denial of service attacks, phishing, and malevolent attacks.

\section{Convenient for the Companies}

- It will ensure the welfare of the staff, members, and stakeholders of the companies.

- It is highly secured due to the usage of encryption techniques and there will be cost-saving as no physical distribution of vouchers is required under this advanced online resolution.

- The redemption of the voucher can be easily detected by the issuers of the e-RUPI.

- It is secure and reliable for the users and the issuing companies.

- Beneficial for Service Providers

- The transactions executed by e-RUPI are real-time transactions, so the amount is credited to the account of service providers on an immediate basis.

\section{Beneficial for sponsors}

- It reinforces the Direct-Benefit Transfer to the beneficiaries and ensures that the process is more transparent and secure.

- No need for the issuance of physical vouchers leads to cost savings as well.

\section{E. Worthy for Hospitals}

- The voucher is approved with the help of verification encryption that makes it easy and secure.

- The usage of this advanced online resolution ensures transactions without a physical interface and smooth completion of transactions. No need to carry cash or cards.

- This advanced online resolution offers faster redemption with limited stages and chances of decline have also been reduced due to the pre-blocked sum.

\section{F. Demerits of e-RUPI}

- The beneficiary of e-RUPI might sell this advanced prepaid voucher to someone else for some consideration who is not the dignified beneficiary, which ultimately infringes the very purpose of this digital money. The ultimate aim of the government is to provide help to needy and deprived people but if the prepaid voucher is sold to another person, then the purpose of this e-RUPI will be hampered.

- It's an advanced digital revolution, so it will be subject to information technology perils such as hacking, sniffing, etc.

\section{Findings}

The e-RUPI is a one-time contactless payment mechanism which is a great initiative by the Indian government in the period of the COVID-19 pandemic. Every digital application comes with its pros and cons. It is observed that the e-RUPI has significant merits such as being secure and reliable for the users and the issuing companies, no need to carry cash or cards, easy redemption, no need for issuance of physical vouchers, the safety of personal data, no internet connection required, use of smartphone is no bar, feature phone can be used, real-time transactions, direct benefit to individuals and no need of bank account. It has numerous benefits for all those who have a stake in e-RUPI transactions. The future of eRUPI is very bright in near future because of its significant merits. It suffers from some demerits also such as the beneficiary of e-RUPI might sell this advanced prepaid voucher to someone else for some consideration who is not the dignified beneficiary, which ultimately infringes the very purpose of this digital money. The ultimate aim of the government is to provide help to needy and deprived people but if the prepaid voucher is sold to another person, then the purpose of this e-RUPI will be hampered.

\section{Conclusion}

e-RUPI is an advanced online resolution that has been launched by the National Payments Corporation of India (NPCI) in collaboration with the Department of Financial Services, Ministry of Health and Family Welfare, National Health Authority, and partner banks. The e-RUPI is not a platform and it is meant for predetermined usage only. The government is planning to launch vouchers for vaccination also. The MSMEs can also use this voucher for the execution of their business-to-business transactions. It is predicted that more banks and acquiring Apps will join this e-governance initiative in near future. This prepaid voucher is previously 
meant for the healthcare sector but because of its vital role in e-governance, its user base will be widened. The private sector can use these vouchers for delivering benefits to their employees. The e-RUPI has noteworthy merits such as security and reliability for the users and the issuing companies, no need to carry cash or cards, easy redemption, no need for issuance of physical vouchers, the safety of personal data, no internet connection required, use of the smart phone is no bar, feature phone can be used, real-time transactions, direct benefit to individuals and no need of bank account. It does suffer from shortcomings such as the beneficiary of the voucher to some other person and helps him in executing the transaction by sharing the SMS or bar code, in consideration of immediate monetary benefit.

\section{Future Implications of e-RUPI in India}

The future of e-RUPI is very bright in near future because of its significant merits. India usually intermediaries took advantage of numerous schemes launched by the government and make lots of money out of it. The poor people are deprived of actual resources and benefits. This initiative by the government will help the individuals to get the direct benefit of all schemes and announcements. This application will be fruitful for all the stakeholders such as banks, customers, sponsors, service providers, government, and companies. India is moving towards the path of digitalization and initiatives in the field of e-governance is the vital step to curb corruption.

\section{References}

[1]. Abu-Shanab, E. A., Harb, Y. A., \& Al-Zoubi, S. Y. (2013). E-government as an anti-corruption tool: citizens perceptions. International Journal of Electronic Governance, 6(3), 232-248.

[2]. Aladwani, A. M. (2016). Corruption as a source of eGovernment projects failure in developing countries: A theoretical exposition. International Journal of Information Management, 36(1), 105-112.

[3]. Andersen, T. B. (2009). E-Government as an anticorruption strategy. Information Economics and policy, 21(3), 201-210.

[4]. Choo, K. K. R. (2015). Cryptocurrency and virtual currency: Corruption and money laundering/terrorism financing risks?. In Handbook of digital currency (pp. 283-307). Academic Press.

[5]. Garg, P., \& Panchal, M. (2017). Study on Introduction of Cashless Economy in India 2016: Benefits \& Challenges. IOSR Journal of business and management, 19(4), 116-120.
[6]. Gilbert, S., \& Loi, H. (2018). Digital currency risk. International Journal of Economics and Finance, 10(2), 108.

[7]. Jain, E. (2014). Technical analysis of Oriental Bank of commerce. SAARJ Journal on Banking \& Insurance Research, 3(2), 76-90.

[8]. Jain, E., \& Lamba, J. (2020). Forensic Accounting: A Way to Fight, Deter and Detect Fraud. IARS'International Research Journal, 10(1).

[9]. Jain, E., \& Lamba, J. (2021). Management and Digitalization Strategy for Transforming Education Sector: An Emerging Gateway Persuaded by COVID-19. In Emerging Challenges, Solutions, and Best Practices for Digital Enterprise Transformation (pp. 69-83). IGI Global.

[10]. Kim, C. K. (2014). Anti-corruption initiatives and e-government: a cross-national study. Public Organization Review, 14(3), 385-396.

[11]. Lamba, J., \& Jain, E. (2021). Advanced Cyber Security and Internet of Things for Digital Transformations of the Indian Healthcare Sector. In Handbook of Research on Advancing Cybersecurity for Digital Transformation (pp. 353-372). IGI Global.

[12]. Mistry, J. J., \& Jalal, A. (2012). An empirical analysis of the relationship between egovernment and corruption. International Journal of Digital Accounting Research, 12.

[13]. Narayanan, H. (2020). Is future a rule of digital currency??? International Journal of Research-GRANTHAALAYAH, 8(8), 96-106.

[14]. Ranade, C. A., \& Joshi, A. (2016). Future of virtual currency in Indian context. International Journal of Marketing and Technology, 6(7), 64-73.

[15]. Setor, T. K., Senyo, P. K., \& Addo, A. (2021). Do digital payment transactions reduce corruption? Evidence from developing countries. Telematics and Informatics, 60, 101577.

[16]. Shah, M. Digital Currency: The Future of Money. International Journal on Recent and Innovation Trends in Computing and Communication, 5(10), 139-141.

[17]. Sidorenko, E. L., \& Lykov, A. A. (2019). Digital Economy and Anti-Corruption: New Digital Models. In SHS Web of Conferences (Vol. 71, p. 0300 


\section{Manuscript Processing Footprints}

\section{A. Journal Volume/Issue Details}

This manuscript it published in Vol. 11 No. 022021 issue of IARS' International Research Journal (I'IRJ).

This is a Peer Reviewed (Refereed) International Journal published by IARS' Press Australia (International Association of Research Scholars) The Volume/Issue is a regular issue of the journal published in August 2021 Available at: https://researth.iars.info/index.php/curie.

\section{B. Copyright, License, and Publishing Rights}

- IARS' Press Australia (International Association of Research Scholars) respects the rights of the authors of research content published with IARS' International Research Journal. The "First Publication Rights" (FPR) to the original work accepted for publication at IARS' International Research Journal is granted to the Publisher of the Journal but copyright for all work published in the journal is retained by the author(s). Works published in the Journal is distributed under a Creative Commons Attribution 4.0 International License (CC B Y 4.0). (This license lets others distribute, remix, adapt, and build upon your work, even commercially, as long as they credit you for the original creation. This is the most accommodating of licenses offered. Recommended for maximum dissemination and use of licensed materials.)

- After publishing the content with IARS' International Research Journal, the author holds complete right on the content for its amendments and reuse in any form. IARS' International Research Journal confirms that author(s) holds the copyright of the content.

- Author(s) grant(s) permission for their work to be indexed in part/full form in commercial and non-commercial indexes. Author(s) grant(s) permission for their work to be harvested in part/full form in commercial and non-commercial archives and distributed through them. Author(s) grant(s) permission for their work to be translated in part/full form in any language and republished and redistributed. Author(s) may enter into separate, additional contractual agreements for the non-exclusive distribution of the published version of the work, with an acknowledgement of its initial publication in this Journal.

- It is the responsibility of the author(s) to secure all necessary copyright and/or permissions for the use of third-party content in their manuscript(s). Author(s) have declared the same at the time of submission of manuscript and 'may also be required' to provide written evidence of this permission anytime in case required for any purposes.

- $\quad$ Publications Ethics and other Terms and Conditions as mentioned on official website of IARS' International Research Journal.

\section{Last Plagiarism Report}

Settings: Similarity of 09 words in a row has been considered plagiarized.

Plagiarized (1\%)

Unique (99\%)

\begin{tabular}{|l|l|}
\hline Date & Aug 13, 2021. \\
\hline Words & 36 Words Plagiarized / Total Words 3546. \\
\hline Source & 3 Source(s) Identified. \\
\hline Remarks & Low similarity detected, check your supervisor if changes are required. \\
\hline
\end{tabular}

Exemption / Relaxation by Editor: None

\section{Processing Track}

\begin{tabular}{|l|l|}
\hline Date of Submission & 03 August 2021 \\
\hline Date of Final Review & 12 August 2021 \\
\hline Date of Acceptance \& Schedule & 15 August 2021 \\
\hline Date of Publishing & 29 August 2021 \\
\hline
\end{tabular}

